\title{
"You Have to do the Best you Can and Hang On" Global Access to Insulin from the User's Perceptive
}

Molly Lepeska, Health Action International, Margaret Ewen, Health Action International, David Beran, University of Geneva

\section{Introduction} Constraints of Insulin Sources and Supply (ACCISS) Study has investigated insulin access from a range of diverse perspectives. One of these perspectives is that of the insulin user. Diabetes is managed by the person living with the condition 95 percent of the time,${ }^{1}$ and thus the user perspective is critical in understanding how insulin is used, what the perceptions of insulin are and what barriers to access and use exist.
Objective | To gain insights on some of the critical issues insulin users have accessing and using insulin across insulin and diabetes types and in multiple countries.

\begin{abstract}
Methods I Informal interviews with insulin users were conducted via phone, Skype, Google Hangout, direct email, and printed hardcopy questionnaires.
\end{abstract}

Results | In total, 36 people were interviewed from 11 countries, 3 high-income countries and 8 low-and middle- income countries. The results found that human insulins are primarily used in lower-income settings, while analogue insulins are used in higher-income settings.

\section{Satisfaction with Insulin}

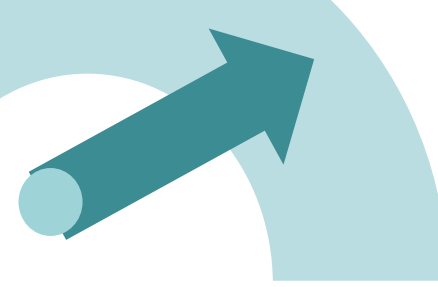

In general people are satisfied with the insulin they are using, regardless of the type. However, this did not equate to not having other issues with their diabetes or insulin management.

"I'm satisfied with what l'm taking... [ [but] often the brand is not available. I tried my best to adjust my diet while looking or waiting for availability."

Tanzania human insulin user, type 2 diabetes

\section{Influence of Doctors and Others}

The interviews highlighted the important impact that both doctors and diabetes associations can have on insulin users in terms of their insulin choices and overall choices in diabetes management.

"No preference (on type of insulin). I trust what my doctors say. What they say I should do, I will do." Mexico analogue insulin user, type 2 diabetes

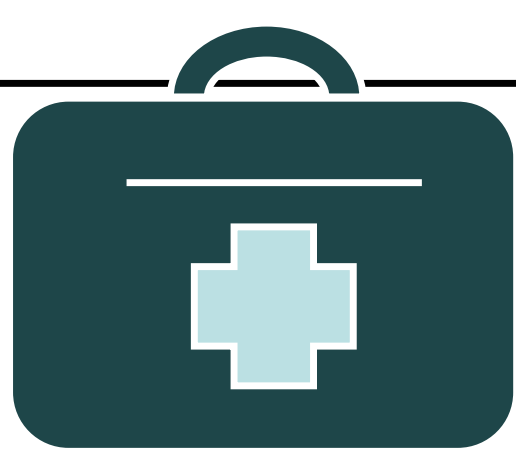

\section{Brand Loyalty}

In terms of willingness to change insulins, brand loyalty seemed more important than company loyalty as most respondents knew the name of their insulin, but not the name of the company that manufactured it. Further, most did not know the differences between human, analogue or animal insulin, or could not identify these types accurately.

“I would [have] reservations [about changing insulins] because I'm used to what II use and because I trust it. Anything else would be a risk. The origin doesn't interest me, it's what I'm using that's keeping me healthy." Canada analogue insulin user type 1 diabetes

\section{Price of Insulin and Supplies}

The interviews revealed that insulin users in 10 of the 11 countries are struggling to pay for insulin and/or diabetes supplies

"I have insurance so I only have a US\$5 co-pay on each $10 \mathrm{ml}$ vial of [lispro]. I pay US $\$ 700$ per month in health insurance for me and my 2 boys. Without insurance my insulin would be apx. $\$ 350$ per bottle." US analogue insulin user, type 1 diabetes

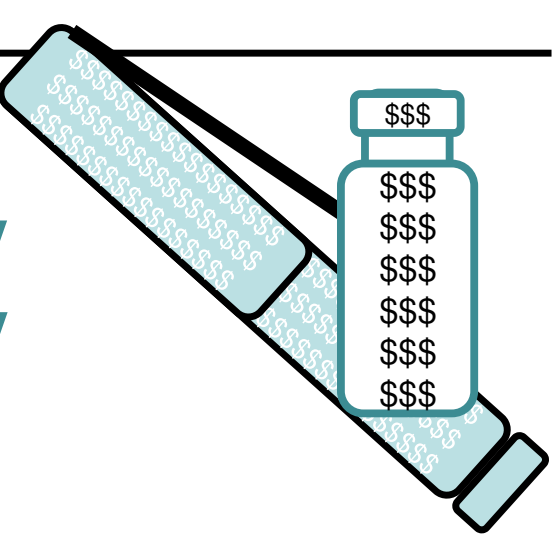

"Insulin is free if it's available through the health unit. If it's not there, it costs 25,000 Ugandan shillings per vial at the private pharmacy (in Kampala). It is also possible to get it sometimes through the diabetes association for 15,000 shillings. But to do this, the diabetes association collects 3,000 shillings a month, which you must pay every month, regardless of if you get insulin or not. Supplies are also expensive. Sometimes they give syringes (1-2 at a time) but sometimes you have to buy. [These] cost 1,000 shillings (per syringe)." Relative of Uganda human insulin user, type 2 diabetes

Discussion | The findings point to certain trends in how insulin is used on a day-to-day basis, particularly on where users receive insulin from, the relationship users have with their doctors, and the perceptions of their treatment. It also points to the shared struggles that insulin users, across countries and type of diabetes, go through, and the opportunity it presents to work together to further the cause of access to affordable high-quality insulin for all. 